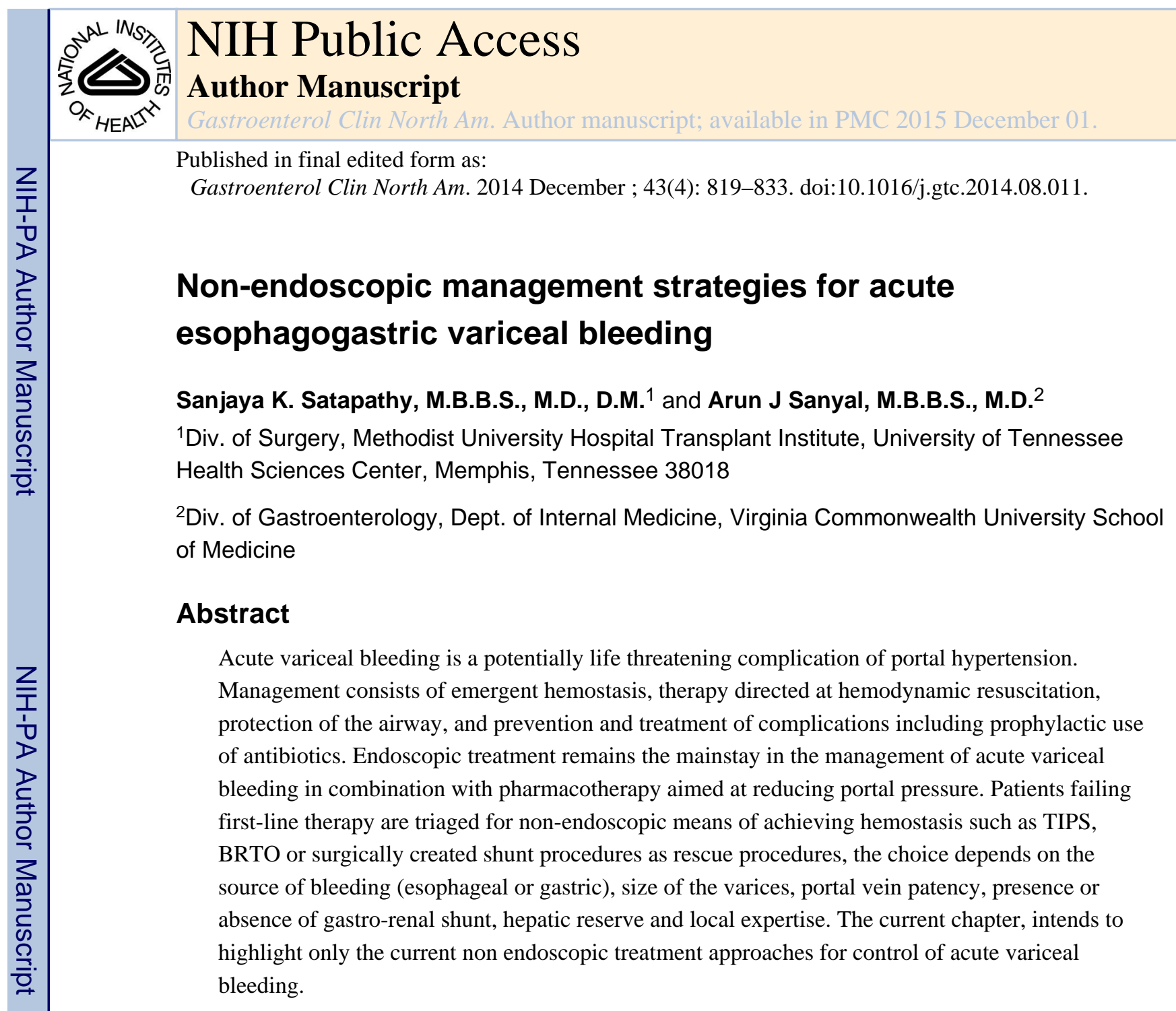

\title{
Keywords
}

Portal hypertension; variceal hemorrhage; variceal bleeding; varices; TIPS; postosytemic shunt; BRTO

\begin{abstract}
Acute variceal bleeding is a potentially life threatening complication of portal hypertension defined as elevation of hepatic venous pressure gradient to $>5 \mathrm{mmHg}$. Portal hypertension (PHT) is classified as pre-hepatic, intra-hepatic or post-hepatic, with intra-hepatic PHT being the form most often caused by cirrhosis, irrespective of etiology ${ }^{1}$. Portal hypertension results in redistribution and increased blood flow through the coronary veins and the short
\end{abstract}

\footnotetext{
(C) 2014 Elsevier Inc. All rights reserved.

Corresponding author: Arun J Sanyal, M.D., Professor of Internal Medicine, Pharmacology and Molecular Pathology, Address: MCV Box 980341, Richmond, VA 23298-0341, Phone: (804) 828 6314, Fax: (804) 828 2992, asanyal@ mcvh-vcu.edu.

Author disclosures:

Authors disclose no direct financial interest in the subject matter discussed in the article. No grants received in preparation of this manuscript.

Publisher's Disclaimer: This is a PDF file of an unedited manuscript that has been accepted for publication. As a service to our customers we are providing this early version of the manuscript. The manuscript will undergo copyediting, typesetting, and review of the resulting proof before it is published in its final citable form. Please note that during the production process errors may be discovered which could affect the content, and all legal disclaimers that apply to the journal pertain.
} 
gastric veins resulting in esophageal and gastric varices. Gastroesophageal varices begin to form at a pressure gradient of 8 to $10 \mathrm{~mm} \mathrm{Hg}$, with bleeding risk increased at a gradient of $12 \mathrm{~mm} \mathrm{Hg}{ }^{1}$. In patients without varices, esophageal varices develop and grow in size at a rate of about $7 \%$ per year as a result of ongoing portal hypertension ${ }^{2,3}$. Variceal rupture could potentially occur in about one third of patients, with the highest rates observed in patients with HVPG > $20 \mathrm{mmHg}^{4}$, large varices with red wale markings ${ }^{5}$ and/or in Child C patients ${ }^{6}$. Acute variceal bleeding occurs in $25 \%$ to $40 \%$ of cirrhotic patients and carries a mortality of $25 \%$ to $30 \%$, making it one of the most dreaded complications of portal hypertension ${ }^{7}$. Bleeding usually occurs at the GE junction as varices are most superficial and have the thinnest wall at this anatomic location. Approximately $50 \%$ of the acute variceal bleeding ceases spontaneously ${ }^{8}$. After an index bleeding episode, most of the episodes of rebleeding occurs in the first 6 weeks ${ }^{9,10}$, and over $50 \%$ of such rebleeding episodes occur within 3 to 4 days from the time of admission for the initial bleeding episode ${ }^{-9}, 11,12,13,14$. The risk factors for early rebleeding are severe initial bleeding as defined by a hemoglobin less than $8 \mathrm{~g} / \mathrm{dL}$, gastric variceal bleeding, thrombocytopenia, encephalopathy, alcohol-related cirrhosis, large varices, active bleeding during endoscopy, and a high $\mathrm{HVPG}^{11,12,13,14,15,16}$. In the long-term, approximately $70 \%$ of subjects experience further variceal bleeding and have a similar risk of mortality within the first year ${ }^{17,18}$. Age greater than 60 years, large esophageal varices, severity of liver disease, continued alcoholism, renal failure, and presence of a hepatoma increase the risk of rebleeding ${ }^{12,19}$.

Before the advent of pharmacotherapy, endoscopic therapy, and shunt procedures for control of variceal bleeding, almost $40 \%$ of patients with acute variceal hemorrhage (AVH) died within 6 weeks, one third rebled at 6 weeks, and only about one third survived beyond 1 year. ${ }^{20}$

Significant advances have been observed in the last two decades in the management of acute variceal bleeding by both endoscopic and non-endoscopic means, and have resulted in significant reductions in both morbidity and mortality from this potentially life threatening condition. Endoscopic treatment is important and remains the cornerstone in the management of acute variceal bleeding, and newer techniques are continuing to evolve. The current article, however, intends to highlight only the current non endoscopic treatment approaches for control of acute variceal bleeding, and recent developments.

\section{MANAGEMENT OF ACUTE VARICEAL BLEEDING GENERAL MANAGEMENT}

Acute variceal bleeding is a potentially life threatening event. Most patients vomit blood but hematochezia and melena might be the only initial symptoms. Hemodynamic stability is dependent on the amount of blood lost, presentation could include symptoms of orthostatic hypotension to hemorrhagic shock. Despite advances in therapy, up to $40 \%$ of patients still die from exsanguinating bleeding. Of note, most deaths are unrelated to bleeding per se and are rather caused by complications of bleeding such as liver failure, infections and hepatorenal syndrome ${ }^{21,22}$. The degree of liver dysfunction, creatinine level, hypovolemic shock, active bleeding on endoscopy, and presence of hepatocellular carcinoma are 
important determinants of adverse outcome ${ }^{21,22,23,24,25}$. Thus, the management of patients with acute variceal bleeding includes not only treatment and control of active bleeding but also the prevention of rebleeding, hepatic encephalopathy, infections and renal failure ${ }^{26}$. Available therapeutic options to control bleeding include medical and endoscopic treatment, balloon tamponade, placement of fully covered self-expandable metallic stents, transjugular intrahepatic portosystemic shunt (TIPS) and surgical shunts. Nowadays, the initial approach is a combination of vasoactive drugs, antibiotics and endoscopic therapy ${ }^{27}$, followed by a more aggressive approach in patients failing first line treatment.

\section{ASSESEMENT OF SEVERITY OF THE BLEEDING}

Assessment of the severity of variceal bleeding is of paramount importance in order to risk stratifying the level of resuscitation. The Baveno II consensus conference ${ }^{28}$ defined an episode of acute variceal bleeding as clinically significant when there is: blood transfusion requirement of at least 2 units and a systolic pressure less than $100 \mathrm{~mm} \mathrm{Hg}$, or a postural drop of $20 \mathrm{~mm} \mathrm{Hg}$ and/or pulse rate greater than 100 beats per minute at time of patient presentation (i.e. time zero). Management of acute variceal hemorrhage includes hemodynamic resuscitation, prevention and treatment of complications, and control of bleeding.

\section{RESCUCIATION}

Correction of hypovolemia-The foremost step is the assessment of intravascular volume loss and replacement with crystalloids and packed red blood cells to keep systolic blood pressure at least at $90-100 \mathrm{mmHg}$, and the heart rate below 100 beats/ min, with a hemoglobin level around 7-8 g/dL (hematocrit of 21-24). Care must be taken to avoid overtransfusion as this can cause a rebound increase in portal pressure and precipitate early rebleeding ${ }^{29,30}$. Fresh frozen plasma and platelets (particularly for a platelet count $<50,000$ $\mathrm{mL}-1$ ) have often been used to correct coagulopathy. These measures do not adequately correct the coagulopathy, and could potentially induce volume overload and rebound portal hypertension ${ }^{31}$. The use of recombinant factor VII has been shown to improve hemostasis rates, but it does not improve survival ${ }^{32}$.

Aspiration precaution-Patients with acute variceal hemorrhage are at very high risk for aspiration pneumonia, which often progresses to multiorgan failure and has been associated with a very high mortality. It is therefore imperative to pay attention to the airway and protect the airway by prophylactic intubation when mental status is impaired, delirium tremens is imminent, or bleeding is too severe for the patient to maintain the integrity of their airway.

\section{PREVENTION AND TREATMENT OF ASSOCIATED COMPLICATIONS}

Antibiotic prophylaxis-Bacterial infection is documented in $30 \%$ to $40 \%$ of cirrhotic patients on admission or within the first week after variceal bleeding, associated with an increased in-hospital mortality ${ }^{33}, 34$. The most common infections in these patients are spontaneous bacterial peritonitis and bacteremia, followed by urinary tract infections and pneumonia. Most infections are due to enterobacteria. ${ }^{33,} 35$ Antibiotic prophylaxis 
significantly increases both the proportion of patients free from infection and the mean survival rate at 14 days $^{35}$.

Currently, it is recommended that short-term antibiotic prophylaxis, a measure that reduces bacterial infections ${ }^{36}$, variceal rebleeding ${ }^{37}$, and death ${ }^{36}$ be used in every patient with cirrhosis admitted with gastrointestinal hemorrhage ${ }^{38,39}$. The choice of antibiotics however is not standardized as different antibiotics have been used in different trials, and given different local antibiotic susceptibility patterns and different availability; it is unlikely that a definitive trial in this area will be performed. Quinolones in uncomplicated patients ${ }^{40}$, and Ceftriaxone in high-risk patients with advanced liver disease (ascites, encephalopathy, jaundice, and malnutrition) or previous therapy with quinolones is a reasonable choice ${ }^{41}$.

Hepatic encephalopathy-Hepatic encephalopathy is frequently precipitated after acute variceal hemorrhage. Digested blood in the GI tract provides a source of extra protein, which are a source of excess ammonia and other toxic amines. Because of portosystemic shunting, the normal first-pass extraction by the liver is decreased, and the circulating levels of these toxins increase, thereby contributing to the development of hepatic encephalopathy. Hepatic encephalopathy is also worsened by sepsis, azotemia, and electrolyte disturbances that can occur in the context of a variceal bleed. Of note, sedation used during endoscopy or for airway intubation may also contribute to altered mental status in such patients.

Management of hepatic encephalopathy in the setting of acute variceal bleeding includes aggressive therapy with Lactulose, either orally or by means of a nasogastric tube in patient with altered mental status once bleeding is controlled and the gut is known to be functional. Although the role of Rifaximin and other antibiotics for the treatment of encephalopathy in the setting of acute variceal bleeding is unclear, recent studies have shown a combination therapy of Lactulose with Rifaximin may be more useful than Lactulose alone ${ }^{42}$. Patients with persistent hepatic encephalopathy especially those with Grade IV hepatic encephalopathy without improvement despite withdrawal of sedation and aggressive use of lactulose, an imaging study of the head (CT scan or MRI) and electroencephalogram (EEG) should be considered.

Acute renal failure-Acute renal failure in a patient with cirrhosis is a severe complication and often a harbinger of death ${ }^{43}$, while serum creatinine is a key component of the model for end-stage liver disease (MELD) score, a well-established predictor of mortality ${ }^{44}$. Renal failure in a patient with acute variceal bleeding is also a predictor of increased mortality, hence physicians should not just focus on the bleeding alone, but measures should be taken to prevent the occurrence of renal failure ${ }^{45}$. The risk of renal failure can be minimized by careful attention to volume status, avoidance and aggressive treatment of sepsis, and avoidance of nephrotoxic drugs. An indwelling catheter should be used to monitor urine output, and the fluids administered should be tailored to maintain an output of at least $50 \mathrm{cc} / \mathrm{h}$.

\section{ACHIEVEMENT OF HEMOSTASIS}

In the context of active bleeding, it is imperative to begin therapy quickly and control bleeding. Several modalities are available as first-line treatment for the achievement of 
hemostasis. These include pharmacologic treatment, endoscopic sclerotherapy, and variceal ligation. Several other modalities of treatment are available in patients failing standard measures as a rescue therapy such as balloon tamponade, placement of esophageal covered metal stent, TIPS, BRTO etc., a detailed discussion of these is beyond the scope of this chapter. Below is a discussion of non-endoscopic measures to achieve hemostasis.

\section{BALLOON TAMPONADE}

Balloon tamponade is aimed at obtaining temporary hemostasis by direct compression of bleeding varices. The use of balloon tamponade for the treatment of acute esophageal variceal bleeding was introduced by Sengstaken et al ${ }^{46}$. The Minnesota-tube is a modified version with an aspiration channel above the esophageal balloon. For uncontrolled bleeding from gastric varices, the Linton-Nicholas tube is preferred ${ }^{47}$. Balloon tamponade is highly successful in stopping bleeding in experienced hands $48,49,50,51,52,53,54$, but recurrence is observed in about $50 \%$ of the patients within 24 hours following deflation of the balloon. Major complications, the most lethal of which is esophageal rupture, have been observed in $6 \%$ to $20 \%$ of patients, ${ }^{55}$ occurring more frequently in series in which tubes were inserted by inexperienced staff. ${ }^{56}$ It should be noted that balloon tamponade is only a bridging procedure for a more definitive procedure later on.

\section{PHARMACOTHERAPY}

Based on the principle of hydromechanics, portal pressure is determined by intravascular resistance and blood flow. In portal hypertension, the intra-hepatic vascular resistance (IHVR) and splanchnic blood flow are the two main contributors to portal pressure ${ }^{57}$. IHVR is under dynamic regulation, postprandial increases in splanchnic blood flow is always associated with an autonomic down-regulation, leading to no alteration in portal pressure. However, in patients with cirrhosis, this delicate balance is lost and the IHVR is significantly up-regulated by mechanical and hemodynamic factors, which is further aggravated by splanchnic vasodilation ${ }^{58}$. The resultant increase in portal pressure is the antecedent to variceal bleeding with its associated morbidity and high mortality ${ }^{59,60}$. Most drugs currently used to treat varices and/or variceal hemorrhage cause splanchnic vasoconstriction leading to a reduction in portal venous inflow and consequently to a decrease in portal pressure.

Vasopressin-Vasopressin (ADH) is a powerful vasoconstrictor that acts at the level of $\mathrm{V} 1$ receptors located in the smooth muscle of the arteries inducing contraction by activating phospholipase $\mathrm{C}$ and increasing cytosolic calcium $\left[\mathrm{Ca}^{++}\right]$through the inositol triphosphate pathway ${ }^{61}$. The ability of vasopressin to control variceal bleeding is caused by powerful splanchnic arteriolar vasoconstriction, which decreases the portal inflow and thus the portal pressure $^{62}$. Unfortunately, vasopressin also causes profound systemic vasoconstriction with increased peripheral resistance and reduced cardiac output, heart rate, and coronary blood flow, leading to myocardial ischemia and/or infarction, cardiac arrhythmias, mesenteric ischemia, extremity ischemia, and cerebrovascular accidents in a sizable proportion of patients. In clinical trials, $32 \%$ to $64 \%$ of the patients treated with vasopressin experienced adverse effects, and almost $25 \%$ had to be taken off the drug. Fatal complications caused by vasopressin also have been reported ${ }^{63.64}$. The systemic vasoconstrictive adverse effects of 
vasopressin may be minimized by the concomitant use of nitrates 65,66 , and 67 . Vasopressin is administered as a continuous infusion at a rate of $0.2-0.4 \mathrm{U} / \mathrm{min}$ that may be increased to 0.6 $\mathrm{U} / \mathrm{min}$ if required. Therapy is maintained for 24 hours after the control of bleeding. Vasopressin rarely is used today in the management of variceal bleeding because of its adverse effect profile.

Terlipressin (Glypressin)—Triglycyl-lysl-vasopressin (Terlipressin), a synthetic analog of vasopressin is in itself inactive but is activated after the glycyl residue is cleaved releasing vasopressin slowly and continuously causing splanchnic vasoconstriction $68,69,70$. Terlipressin has a longer biological half-life and is administered every 4 hours, and thus continuous infusion is not needed. Terlipressin does not increase the plasminogen activator activity, as is seen with vasopressin, but has similar effects on the coronary vasculature.

Somatostatin and analogs-Somatostatin is a naturally occurring peptide originally named for its growth hormone-inhibiting properties ${ }^{71,72}$. Somatostatin causes an increase in splanchnic vascular resistance by causing vasoconstriction resulting in decrease in the portal blood inflow. The vasoconstriction is mediated by inhibiting the release of splanchnic vasodilator hormones like glucagon and vasoactive intestinal peptide ${ }^{73,74}$. In addition, somatostatin also acts by preventing postprandial hyperemia, and also causes a modest decrease in the hepatic blood flow and the wedged hepatic venous pressure (WHVP) $75,76,77,78,79$. Somatostatin has a short half-life and is rapidly cleared from the blood. Somatostatin is given as an intravenous bolus of $250 \mu \mathrm{g}$, followed by a continuous infusion of $250 \mu \mathrm{g} / \mathrm{h}$; the therapy is continued for 2 to 5 days if successful. A bolus of somatostatin markedly decreases the hepatic venous pressure gradient by $52 \%$ at 1 minute, $19 \%$ at 3 minutes, and by $13 \%$ at 5 minutes ${ }^{80}$.

In current clinical practice and clinical trials the synthetic analogs of somatostatin, namely, octreotide and vapreotide, have been most widely used in the management of acute variceal bleeding and have a longer duration of action. Octreotide produces a modest decline in the WHVP $^{81}$ and a variable effect on intravariceal pressure ${ }^{82}$. Additionally, it significantly decreases azygous blood flow and has an excellent safety profile in the absence of the systemic circulatory adverse effects as seen with vasopressin. Octreotide is a synthetic analogue of somatostatin with longer half-life. It is administered as an initial bolus of $50 \mu \mathrm{g}$, followed by an infusion of $50 \mu \mathrm{g} / \mathrm{h}{ }^{83}$. The complication rates with somatostatin and octreotide are few, but can include mild hyperglycemia and abdominal cramping.

\section{RADILOGICAL INTERVENTION}

\section{A. Transjugular intrahepatic portosystemic shunt (TIPS) for acute variceal} bleeding - Transjugular intrahepatic portosystemic shunt (TIPS) is an artificial channel within the liver that establishes communication between the inflow portal vein and the outflow hepatic vein. The procedure is usually performed by an interventional radiologist, who creates the shunt using a fluroscopy-guided endovascular approach, with the jugular vein as the usual entry site, from which a catheter is advanced to gain access to the patient's hepatic vein by traveling from the superior vena cava into the inferior vena cava and finally the hepatic vein. Once the catheter is in the hepatic vein, a branch of the portal vein within 
the liver is then catheterized with placement of an expandable stent from the hepatic vein into the branch of the portal vein. The success rate with TIPS for decompression of the portal vein is high — more than $90 \%$ of cases in most case series. ${ }^{84,85,86,87,88,89,90}$ Guidelines have been established by the Society of Interventional Radiology for creation of a TIPS, and the consensus was that a technically successful outcome is creation of the shunt with a decrease in portal pressure to $<12 \mathrm{~mm} \mathrm{Hg}$ that should be achieved in $95 \%$ of patients, and resolution of the complication of portal hypertension should be achieved in $90 \%$ of cases. ${ }^{91,92}$

In general, pharmacologic therapy and endoscopic banding achieves control of variceal bleeding in the vast majority of cases, failures to standard therapy occur in about $10 \%-20 \%$ of patients, and it in these sub groups TIPS could potentially be lifesaving. As reported earlier, the success rate of TIPS to achieve decompression of the portal vein is more than $90 \% 93,94,95,96,97,98,99$, nevertheless, mortality at 6 weeks among patients treated with rescue TIPS for uncontrolled index bleeding and rebleeding is very high (35\%), reflecting the severity of their underlying liver disease as well as additional organ dysfunction that may have occurred owing to hypotension, infection, and aspiration ${ }^{100}$.

It is thus important to identify patients at high risk of failing standard therapy, as these patients could potentially be offered TIPS early on. The most important predictor of failure to standard therapy is HVPG $>20 \mathrm{~mm} \mathrm{Hg}$ measured within 24 hours of admission ${ }^{101}, 102$. Unfortunately such measurements are not feasible in most centers, and Child's status is used as a surrogate marker, as Child's $\mathrm{C}$ status correlates with the likelihood of having an HVPG above $20 \mathrm{mmHg}$ in more than $85 \%$ of patients ${ }^{102}$. In order to verify the utility of preemptive TIPS, two trials in patients with acute variceal hemorrhage at high risk of failing standard therapy were conducted. In the first, a single-center trial, 52 patients with an HVPG above $20 \mathrm{mmHg}$ were randomized to (uncoated) TIPS within 24 hours of admission versus continuing standard therapy. ${ }^{103}$ In the second trial, a multicenter European study, 63 Child class $\mathrm{C}$ patients (excluding those with the highest scores of 14 and 15) or Child class B patients with active bleeding were randomized to (polytetrafluoroethylene-coated) TIPS within 24 to 72 hours of admission versus continued standard therapy. ${ }^{104}$ Both trials showed a significant advantage of TIPS with a reduction in composite outcomes (failure to control bleeding or early rebleeding) and, importantly, a significantly higher survival. Usefulness of early TIPS in acute variceal hemorrhage and high risk of treatment failure has been further confirmed in a recent retrospective trial with a lower incidence of failure to control bleeding or rebleeding as well as reduced mortality ${ }^{105}$. These studies led to the recommendation for patients with variceal bleeding who are Child class C (14 points) or are Child class B with active bleeding that early (preemptive) TIPS ( $<72$ hours) should be considered ${ }^{106}$ [Figure 1]. A recent economic modeling study has further confirmed early TIPS insertion is to be a cost-effective intervention in selected high risk patients ${ }^{107}$. Importantly, the subpopulation of patients with variceal bleeding who would be candidates for early TIPS represent less than $20 \%$ of the patients admitted with this complication. In the rest of the patients, the majority, TIPS is considered second-line therapy and is reserved for patients who fail standard therapy. 
B. Balloon-Occluded Retrograde Transvenous Obliteration (BRTO)-The BRTO procedure is an endovascular technique that causes occlusion of outflow portosystemic shunt, such as a gastrorenal shunt, using an occlusion balloon followed by the endovascular injection of a sclerosing agent directly into the gastro-variceal system/ complex. ${ }^{108,109,100,111,112}$ For the conventional BRTO procedure, a large infradiaphragmatic "left-sided" portosystemic collateral is required. ${ }^{13,114,115}$ The most common shunt to be occluded during a conventional BRTO procedure is a gastrorenal shunt, which provides venous outflow in $90 \%$ of gastric varices cases. The remaining $10 \%$ of gastric varices drain through a gastrocaval shunt (infra-diaphragmatically) or other less common transdiaphragmatic veins. Preprocedural imaging is important in assessing the sites, types, and morphology of these portosystemic shunts. ${ }^{116}$

Bleeding esophageal varices that cannot be controlled medically and endoscopically would warrant a TIPS procedure and not a BRTO. ${ }^{117,118}$ Bleeding from gastric varices that are small and exhibit slow flow by endoscopic Doppler ultrasound (EUS) can be sclerosed (or "glued") endoscopically and may not necessarily require a BRTO procedure. However, if there are large fundal and/or cardia gastric varices exhibiting high flow, some endoscopists would defer to a BRTO procedure due to concerns about causing intravascular (usually systemic venous) non-target embolization of the sclerosant. Obviously, if bleeding is from combined gastric and esophageal varices, then the esophageal varices can be managed by endoscopy and large high-flow gastric varices could be managed by BRTO. In the presence of large high-flow gastric varices and prominent but not bleeding esophageal varices, preemptive esophageal variceal banding may be warranted because BRTO exacerbates portal hypertension and may aggravate esophageal varices. ${ }^{119,120,121}$

Portal vein thombosis creates a special situation, and risks, benefits of BRTO should be carefully considered in the presence of portal vein thrombosis. Gastrorenal shunts and splenorenal shunts, if present, are portosystemic collaterals that naturally occur and promote hepatofugal flow. In the presence of a thrombosed main portal vein, occlusion of the gastrorenal shunt, a by-product of the BRTO procedure, would potentially cause mesenteric venous hypertension, mesenteric ischemia, and possibly thrombosis of the entire splanchnic portal venous circulation. Chronic occlusion of the main portal vein with cavernous transformation may provide sufficient outflow for the portal venous system after occluding the portosystemic shunts, and therefore it may be acceptable to proceed with the BRTO. ${ }^{116}$

BRTO has shown considerable effectiveness in controlling gastric variceal bleeding with low rebleed rates. It has many advantages versus TIPS in that it is less invasive and can be performed on patients with poor hepatic reserve and encephalopathy (and may even improve both). However, its by-product is occlusion of a spontaneous hepatofugal (TIPS equivalent) shunt and could potentially increase in portal hypertension with aggravation of esophageal varices and ascites. With the increasing experience with the management of gastric varices a tailored approach based on the anatomy of the patient, clinical features of portal hypertension, and hepatic reserve management can be better selected for either endoscopy, TIPS, or BRTO. 


\section{SURGICAL PROCEDURES}

Surgical procedures in patients with acute or recurrent variceal bleeding are limited to a very small portion of patients in whom medical and/or endoscopic control of bleeding was not achievable and in situations when TIPS is not an option because of technical or anatomic problems such as complete thrombosis of the portal vein. Surgical procedures are primarily based on creation of a shunt to decompress the portal vasculature or non-shunt operations such as esophageal transection or devascularization of the gastroesophageal junction. Shunt operations have been further categorized as nonselective if they derive all portal blood flow to the inferior vena cava bypassing the liver, such as portacaval shunt, and selective if they are intended to at least partly preserve the portal blood flow to the liver, such as the distal splenorenal shunt or the calibrated small-diameter portacaval H-graft shunt. It is to be noted that despite such categorization, the selectivity of these shunts is never completely achieved or is mostly lost during follow-up ${ }^{122}$. It is probably for these reasons, no major differences in clinical outcomes among these 2 types of shunt are found at medium- or long-term follow-up. ${ }^{2}$

Portal decompressive surgery and esophageal transection are highly effective in achieving hemostasis ${ }^{123,124}$. However, despite the success in controlling bleeding, the mortality of these patients is still high (approximately 45\%-75\%). ${ }^{123,124}$ Not uncommonly patients surviving these episodes are fraught with chronic or recurrent portal systemic encephalopathy, ${ }^{123}$ The calibrated small-diameter portacaval $\mathrm{H}$-graft shunt has reduced encephalopathy in comparison with total portocaval shunt in the only randomized controlled trial reported. ${ }^{125}$ In addition, portacaval shunts alter vascular anatomy, which further complicates future liver transplant surgery.

\section{CONCLUSION}

Variceal bleeding is a potentially life threatening complication of portal hypertension. Patients presenting with acute bleeding not only needs attention for treatment directed at emergent hemostasis, but also needs therapy directed at hemodynamic resuscitation, protection of the airway, prevention, and treatment of complications including prophylactic use of antibiotics. Currently available first line treatment for acute esophageal variceal bleeding includes a combination of non-endoscopic treatment aimed at reducing portal pressure as well as endoscopic treatment with band ligation, sclerotherapy. Patients failing first-line therapy are triaged for TIPS, or surgically created shunts as rescue procedures. Balloon tamponade and use of self-expandable metal stents are used as a bridge to more definitive treatment. Management of gastric varices is particularly challenging, treatment includes early institution of pharmacotherapy, in combination with endoscopic therapy with cyanoacrylate, TIPS, and BRTO. This choice depends on the size of the varices, portal vein patency, presence or absence of gastro-renal shunt, hepatic reserve and local expertise. Advances in pharmacologic agents, improved endoscopic techniques, and advances in the use of coated stents for TIPS will hopefully pave the way for improved control of hemostasis, ultimately further reducing the morbidity and mortality in patients with acute variceal bleeding. Ultimately, liver transplantation remains the only definitive treatment and provides long-term survival in those who have advanced liver failure and variceal bleeding. 


\section{References}

1. Garcia-Tsao G, Groszmann RJ, Fisher RL, et al. Portal pressure, presence of gastroesophageal varices and variceal bleeding. Hepatology. 1985; 5:419-24. [PubMed: 3873388]

2. Groszmann RJ, Garcia-Tsao G, Bosch J, et al. Beta-blockers to prevent gastroesophageal varices in patients with cirrhosis. N Engl J Med. 2005; 353:2254-61. [PubMed: 16306522]

3. Merli M, Nicolini G, Angeloni S, et al. Incidence and natural history of small esophageal varices in cirrhotic patients. J Hepatol. 2003; 38:266-72. [PubMed: 12586291]

4. Moitinho E, Escorsell A, Bandi JC, et al. Prognostic value of early measurements of portal pressure in acute variceal bleeding. Gastroenterology. 1999; 117:626-631. [PubMed: 10464138]

5. Beppu K, Inokuchi K, Koyanagi N, et al. Prediction of variceal hemorrhage by esophageal endoscopy. Gastrointest Endosc. 1981; 27:213-218. [PubMed: 6975734]

6. North Italian Endoscopic Club for the Study and Treatment of Esophageal Varices. Prediction of the first variceal hemorrhage in patients with cirrhosis of the liver and esophageal varices. A prospective multicenter study. N Engl J Med. 1988; 319:983-989. [PubMed: 3262200]

7. Wright AS, Rikkers LF. Current management of portal hypertension. J Gastrointest Surg. 2008; 9:992-1005. [PubMed: 16137597]

8. Prandi D, Rueff B, Roche-Sicot J, et al. Life-threatening hemorrhage of the digestive tract in cirrhotic patients. An assessment of the postoperative mortality after emergency portacaval shunt. Am J Surg. 1976; 131:204-209. [PubMed: 1082722]

9. Graham DY, Smith JL. The course of patients after variceal hemorrhage. Gastroenterology. 1981; 80:800-809. [PubMed: 6970703]

10. Smith JL, Graham DY. Variceal hemorrhage: a critical evaluation of survival analysis. Gastroenterology. 1982; 82:968-973. [PubMed: 7037525]

11. McCormick PA, Jenkins SA, McIntyre N, et al. Why portal hypertensive varices bleed and bleed: a hypothesis. Gut. 1995; 36:100-103. [PubMed: 7890210]

12. de Franchis R, Primignani M. Why do varices bleed? Gastroenterol Clin North Am. 1992; 21:85101. [PubMed: 1568779]

13. Pagliaro L, D’Amico G, Luca A, et al. Portal hypertension: diagnosis and treatment. J Hepatol. 1995; 23:36-44. [PubMed: 8551010]

14. Boyer TD. Natural history of portal hypertension. Clin Liver Dis. 1997; 1:31-44. [PubMed: 15562666]

15. Sarin SK, Lahoti D, Saxena SP, et al. Prevalence, classification, and natural history of gastric varices: a long-term follow-up study in 568 portal hypertension patients. Hepatology. 1992; 16:1343-1349. [PubMed: 1446890]

16. Ready JB, Robertson AD, Goff JS, et al. Assessment of the risk of bleeding from esophageal varices by continuous monitoring of portal pressure. Gastroenterology. 1991; 100:1403-1410. [PubMed: 2013385]

17. Burroughs AK, Jenkins WJ, Sherlock S, et al. Controlled trial of propranolol for the prevention of recurrent variceal hemorrhage in patients with cirrhosis. N Engl J Med. 1983; 309:1539-1542. [PubMed: 6361553]

18. Burroughs AK, McCormick PA. Prevention of variceal rebleeding. Gastroenterol Clin North Am. 1992; 21:119-147. [PubMed: 1349003]

19. de Dombal FT, Clarke JR, Clamp SE, et al. Prognostic factors in upper GI bleeding. Endoscopy. 1986; 18:6-10. [PubMed: 3519197]

20. Graham DY, Smith JL. The course of patients after variceal hemorrhage. Gastroenterology. 1981; 80:800-9. [PubMed: 6970703]

21. Augustin S, Muntaner L, Altamirano JT, et al. Predicting early mortality after acute variceal hemorrhage based on classification and regression tree analysis. Clin Gastroenterol Hepatol. 2009; 7:1347-1354. [PubMed: 19699816]

22. D'Amico G, De Franchis R. Upper digestive bleeding in cirrhosis. Post-therapeutic outcome and prognostic indicators. Hepatology. 2003; 38:599-612. [PubMed: 12939586] 
23. Augustin S, Altamirano J, González A, et al. Effectiveness of combined pharmacologic and ligation therapy in high-risk patients with acute esophageal variceal bleeding. Am J Gastroenterol. 2011; 106:1787-1795. [PubMed: 21625271]

24. Bernard B, Cadranel JF, Valla D, et al. Prognostic significance of bacterial infection in bleeding cirrhotic patients: a prospective study. Gastroenterology. 1995; 108:1828-1834. [PubMed: 7768389]

25. Cárdenas A, Ginès P, Uriz J, et al. Renal failure after upper gastrointestinal bleeding in cirrhosis: incidence, clinical course, predictive factors, and short-term prognosis. Hepatology. 2001; 34:671676. [PubMed: 11584362]

26. García-Pagán JC, Reverter E, Abraldes JG, et al. Acute variceal bleeding. Semin Respir Crit Care Med. 2012; 33:46-54. [PubMed: 22447260]

27. Bañares R, Albillos A, Rincón D, et al. Endoscopic treatment versus endoscopic plus pharmacologic treatment for acute variceal bleeding: a meta-analysis. Hepatology. 2002; 35:609615. [PubMed: 11870374]

28. de Franchis R. Developing consensus in portal hypertension. J Hepatol. 1996; 25(3):390-4. [PubMed: 8895020]

29. Kravetz D, Bosch J, Arderiu M, et al. Hemodynamic effects of blood volume restitution following a hemorrhage in rats with portal hypertension due to cirrhosis of the liver: influence of the extent of portal-systemic shunting. Hepatology. 1989; 9:808-814. [PubMed: 2714733]

30. Kravetz D, Sikuler E, Groszmann RJ. Splanchnic and systemic hemodynamics in portal hypertensive rats during hemorrhage and blood volume restitution. Gastroenterology. 986; 90:1232-1240. [PubMed: 3956942]

31. Youssef WI, Salazar F, Dasarathy S, et al. Role of fresh frozen plasma infusion in correction of coagulopathy of chronic liver disease: a dual phase study. Am J Gastroenterol. 2003; 98:13911394. [PubMed: 12818286]

32. Bosch J, Thabut D, Bendtsen F, et al. Recombinant factor VIIa for upper gastrointestinal bleeding in patients with cirrhosis: a randomized, double-blind trial. Gastroenterology. 2004; 127:11231130. [PubMed: 15480990]

33. Bernard B, Cadranel JF, Valla D, et al. Prognostic significance of bacterial infection in bleeding cirrhotic patients: a prospective study. Gastroenterology. 1995; 108:1828-1834. [PubMed: 7768389]

34. Deschenes M, Villeneuve JP. Risk factors for the development of bacterial infections in hospitalized patients with cirrhosis. Am J Gastroenterol. 1999; 94:2193-2197. [PubMed: 10445549]

35. Soares-Weiser K, Brezis M, Tur-Kaspa R, et al. Antibiotic prophylaxis of bacterial infections in cirrhotic inpatients: a meta-analysis of randomized controlled trials. Scand J Gastroenterol. 2003; 38:193-200. [PubMed: 12678337]

36. Bernard B, Grange JD, Khac EN, et al. Antibiotic prophylaxis for the prevention of bacterial infections in cirrhotic patients with gastrointestinal bleeding: A meta-analysis. Hepatology. 1999; 29:1655-1661. [PubMed: 10347104]

37. Hou MC, Lin HC, Liu TT, et al. Antibiotic prophylaxis after endoscopic therapy prevents rebleeding in acute variceal hemorrhage: a randomized trial. Hepatology. 2004; 39:746-753. [PubMed: 14999693]

38. de Franchis R. Evolving consensus in portal hypertension report of the Baveno IV consensus workshop on methodology of diagnosis and therapy in portal hypertension. J Hepatol. 2005; 43:167-176. [PubMed: 15925423]

39. Garcia-Tsao G, Sanyal AJ, Grace ND, et al. Practice Guidelines Committee of the American Association for the Study of Liver Diseases. Practice Parameters Committee of the American College of Gastroenterology. Prevention and management of gastroesophageal varices and variceal hemorrhage in cirrhosis. Hepatology. 2007; 46:922-938. [PubMed: 17879356]

40. Rimola A, García-Tsao G, Navasa M, et al. Diagnosis, treatment and prophylaxis of spontaneous bacterial peritonitis: a consensus document. International Ascites Club. J Hepatol. 2000; 32:142153. [PubMed: 10673079] 
41. Fernández J, Ruiz del Arbol L, Gómez C, et al. Norfloxacin vs ceftriaxone in the prophylaxis of infections in patients with advanced cirrhosis and hemorrhage. Gastroenterology. 2006; 131:10491056. quiz 1285. [PubMed: 17030175]

42. Sharma BC, Sharma P, Lunia MK, et al. A randomized, double-blind, controlled trial comparing rifaximin plus lactulose with lactulose alone in treatment of overt hepatic encephalopathy. Am J Gastroenterol. 2013; 108(9):1458-63. [PubMed: 23877348]

43. Cardenas A, Gines P, Uriz J, et al. Renal failure after upper gastrointestinal bleeding in cirrhosis: incidence, clinical course, predictive factors, and short-term prognosis. Hepatology. 2001; 34(4 Pt 1):671-6. [PubMed: 11584362]

44. Kremers WK, van IJperen M, Kim WR, et al. MELD score as a predictor of pretransplant and posttransplant survival in OPTN/UNOS status 1 patients. Hepatology. 2004; 39:764-9. [PubMed: 14999695]

45. Fallatah HI, Al Nahdi H, Al Khatabi M, et al. Variceal hemorrhage: Saudi tertiary center experience of clinical presentations, complications and mortality. World J Hepatol. 2012; 4:26873. [PubMed: 23060972]

46. Sengstaken RW, Blakemore AH. Balloon tamponage for the control of hemorrhage from esophageal varices. Ann Surg. 1950; 131:781-789. [PubMed: 15411151]

47. Terés J, Cecilia A, Bordas JM, et al. Esophageal tamponade for bleeding varices. Controlled trial between the Sengstaken-Blakemore tube and the Linton-Nachlas tube. Gastroenterology. 1978; 75:566-569. [PubMed: 361485]

48. Panés J, Terés J, Bosch J, Rodés J. Efficacy of balloon tamponade in treatment of bleeding gastric and esophageal varices. Results in 151 consecutive episodes. Dig Dis Sci. 1988; 33:454-459. [PubMed: 3280273]

49. Cook D, Laine L. Indications, technique, and complications of balloon tamponade for variceal gastrointestinal bleeding. J Intensive Care Med. 1992; 7:212-218. [PubMed: 10147943]

50. Chojkier M, Conn HO. Esophageal tamponade in the treatment of bleeding varices. A decadel progress report. Dig Dis Sci. 1980; 25:267-272. [PubMed: 6967005]

51. Hunt PS, Korman MG, Hansky J, et al. An 8-year prospective experience with balloon tamponade in emergency control of bleeding esophageal varices. Dig Dis Sci. 1982; 27:413-416. [PubMed: 7042254]

52. Fort E, Sautereau D, Silvain C, et al. A randomized trial of terlipressin plus nitroglycerin vs. balloon tamponade in the control of acute variceal hemorrhage. Hepatology. 1990; 11:678-681. [PubMed: 2109729]

53. Paquet KJ, Feussner H. Endoscopic sclerosis and esophageal balloon tamponade in acute hemorrhage from esophagogastric varices: a prospective controlled randomized trial. Hepatology. 1985; 5:580-583. [PubMed: 3894199]

54. Pitcher JL. Safety and effectiveness of the modified Sengstaken-Blakemore tube: a prospective study. Gastroenterology. 1971; 61:291-298. [PubMed: 5315474]

55. D'Amico G, Pagliaro L, Bosch J, et al. The treatment of portal hypertension: a meta-analytic review. Hepatology. 1995; 22:332-354. [PubMed: 7601427]

56. Chojkier M, Conn HO. Esophageal tamponade in the treatment of bleeding varices. A decadel progress report. Dig Dis Sci. 1980; 25:267-272. [PubMed: 6967005]

57. Cichoz-Lach H, Celiński K, Słomka M, et al. Pathophysiology of portal hypertension. J Physiol Pharmacol. 2008; 59 (Suppl 2):231-238. [PubMed: 18812641]

58. Moneta GL, Taylor DC, Helton WS, et al. Duplex ultrasound measurement of postprandial intestinal blood flow: effect of meal composition. Gastroenterology. 1988; 95:1294-1301. [PubMed: 3049214]

59. Albillos A, Bañares R, González M, et al. The extent of the collateral circulation influences the postprandial increase in portal pressure in patients with cirrhosis. Gut. 2007; 56:259-264. [PubMed: 16837532]

60. Bellis L, Berzigotti A, Abraldes JG, et al. Low doses of isosorbide mononitrate attenuate the postprandial increase in portal pressure in patients with cirrhosis. Hepatology. 2003; 37:378-384. [PubMed: 12540788] 
61. Schmid PG, Sharabi FM, Guo GB, et al. Vasopressin and oxytocin in the neural control of the circulation. Fed Proc. 1984; 43:97-102. [PubMed: 6690343]

62. Reichen J. Liver function and pharmacological considerations in pathogenesis and treatment of portal hypertension. Hepatology. 1990; 11:1066-1078. [PubMed: 2194921]

63. Kravetz D, Bosch J, Teres J, et al. Comparison of intravenous somatostatin and vasopressin infusions in treatment of acute variceal hemorrhage. Hepatology. 1984; 4:442-446. [PubMed: 6144625]

64. Conn HO, Ramsby GR, Storer EH, et al. Intra-arterial vasopressin in the treatment of upper gastrointestinal hemorrhage: a prospective, controlled clinical trial. Gastroenterology. 1975; 68:211-221. [PubMed: 803910]

65. Tsai YT, Lay CS, Lai KH, et al. Controlled trial of vasopressin plus nitroglycerin vs. vasopressin alone in the treatment of bleeding esophageal varices. Hepatology. 1986; 6:406-409. [PubMed: 3086203]

66. Gimson AE, Westaby D, Hegarty J, et al. A randomized trial of vasopressin and vasopressin plus nitroglycerin in the control of acute variceal hemorrhage. Hepatology. 1986; 6:410-413. [PubMed: 3086204]

67. Bosch J, Groszmann RJ, Garcia-Pagan JC, et al. Association of transdermal nitroglycerin to vasopressin infusion in the treatment of variceal hemorrhage: a placebo-controlled clinical trial. Hepatology. 1989; 10:962-968. [PubMed: 2511136]

68. Burroughs AK, Panagou E. Pharmacological therapy for portal hypertension: rationale and results. Semin Gastrointest Dis. 1995; 6:148-164. [PubMed: 7551972]

69. de Franchis, R., editor. Portal hypertension II: proceedings of IInd Baveno consensus workshop on definitions, methodology, and therapeutic strategies. Oxford Blackwell Science; 1996. Drug therapy for portal hypertension: A five year review.

70. Blei AT. Vasopressin analogs in portal hypertension: different molecules but similar questions. Hepatology. 1986; 6:146-147. [PubMed: 3510949]

71. Bloom SR, Polak JM. Somatostatin. Br Med J (Clin Res Ed). 1987; 295:288-290.

72. Brazeau P, Vale W, Burgus R, et al. Hypothalamic polypeptide that inhibits the secretion of immunoreactive pituitary growth hormone. Science. 1973; 179:77-79. [PubMed: 4682131]

73. Reichlin S. Somatostatin. N Engl J Med. 1983; 309:1495-1501. [PubMed: 6139753]

74. Reichlin S. Somatostatin (second of two parts). N Engl J Med. 1983; 309:1556-1563. [PubMed: 6140639]

75. Baxter JN, Jenkins SA. Somatostatin: an alternative to sclerotherapy? Scand J Gastroenterol Suppl. 1994; 207:17-22. [PubMed: 7701262]

76. Merkel C, Gatta A, Zuin R, et al. Effect of somatostatin on splanchnic hemodynamics in patients with liver cirrhosis and portal hypertension. Digestion. 1985; 32:92-98. [PubMed: 2864299]

77. Consolo F, Pustorino S. Theoretical and physiopharmacological bases of the somatostatin treatment in digestive diseases [Italian]. Minerva Chir. 1992; 47:723-729. [PubMed: 1351277]

78. Hanisch E, Doertenbach J, Usadel KH, et al. Somatostatin in acute bleeding oesophageal varices. Pharmacology and rationale for use. Drugs. 1992; 44:24-35. [PubMed: 1385068]

79. Sieber CC, Stalder GA. Pathophysiological and pharmacotherapeutic aspects of portal hypertension [German]. Schweiz Med Wochenschr. 1993; 123:3-13. [PubMed: 8093646]

80. Cirera I, Feu F, Luca A, et al. Effects of bolus injections and continuous infusions of somatostatin and placebo in patients with cirrhosis: a double-blind hemodynamic investigation. Hepatology. 1995; 22:106-111. [PubMed: 7601400]

81. McKee R. A study of octreotide in oesophageal varices. Digestion. 1990; 45:60-64. [PubMed: 2185967]

82. Jenkins SA, Baxter JN, Corbett WA, et al. Effects of a somatostatin analogue SMS 201-995 on hepatic haemodynamics in the pig and on intravariceal pressure in man. Br J Surg. 1985; 72:10091012. [PubMed: 2867802]

83. Abraldes JG, Bosch J. Somatostatin and analogues in portal hypertension. Hepatology. 2002; 35:1305-1312. [PubMed: 12029614] 
84. Boyer TD. Transjugular intrahepatic portosystemic shunt: current status. Gastroenterology. 2003; 124:1700-1710. [PubMed: 12761727]

85. Rössle M, Haag K, Ochs A, et al. The transjugular intrahepatic portosystemic stent-shunt procedure for variceal bleeding. N Engl J Med. 1994; 330:165-171. [PubMed: 8264738]

86. Luketic VA, Sanyal AJ. Esophageal varices. II. TIPS (transjugular intrahepatic portosystemic shunt) and surgical therapy. Gastroenterol Clin N Am. 2000; 29:387-421.

87. Cello JP, Ring EJ, Olcott EW, et al. Endoscopic sclerotherapy compared with percutaneous transjugular intrahepatic portosystemic shunt after initial sclerotherapy in patients with acute variceal hemorrhage. A randomized, controlled trial. Ann Intern Med. 1997; 126:858-865. [PubMed: 9163286]

88. Sanyal AJ, Freedman AM, Luketic VA, et al. Transjugular intrahepatic portosystemic shunts compared with endoscopic sclerotherapy for the prevention of recurrent variceal hemorrhage. A randomized, controlled trial. Ann Intern Med. 1997; 126:849-857. [PubMed: 9163285]

89. Cabrera J, Maynar M, Granados R, et al. Transjugular intrahepatic portosystemic shunt versus sclerotherapy in the elective treatment of variceal hemorrhage. Gastroenterology. 1996; 110:832839. [PubMed: 8608893]

90. Barton RE, Rosch J, Saxon RR, et al. TIPS: short- and long-term results: a survey of 1750 patients. Semin Interv Radiol. 1995; 12:364-367.

91. Haskal ZJ, Martin L, Cardella JF, et al. Quality improvement guidelines for transjugular intrahepatic portosystemic shunts. J Vasc Interv Radiol. 2001; 12:131-136. [PubMed: 11265875]

92. Haskal ZJ, Martin L, Cardella JF, et al. Quality improvement guidelines for transjugular intrahepatic portosystemic shunts. J Vasc Interv Radiol. 2003; 14:S265-S270. [PubMed: 14514831]

93. Boyer TD. Transjugular intrahepatic portosystemic shunt: current status. Gastroenterology. 2003; 124:1700-1710. [PubMed: 12761727]

94. Rössle M, Haag K, Ochs A, et al. The transjugular intrahepatic portosystemic stent-shunt procedure for variceal bleeding. N Engl J Med. 1994; 330:165-171. [PubMed: 8264738]

95. Luketic VA, Sanyal AJ. Esophageal varices. II. TIPS (transjugular intrahepatic portosystemic shunt) and surgical therapy. Gastroenterol Clin N Am. 2000; 29:387-421.

96. Cello JP, Ring EJ, Olcott EW, et al. Endoscopic sclerotherapy compared with percutaneous transjugular intrahepatic portosystemic shunt after initial sclerotherapy in patients with acute variceal hemorrhage. A randomized, controlled trial. Ann Intern Med. 1997; 126:858-865. [PubMed: 9163286]

97. Sanyal AJ, Freedman AM, Luketic VA, et al. Transjugular intrahepatic portosystemic shunts compared with endoscopic sclerotherapy for the prevention of recurrent variceal hemorrhage. A randomized, controlled trial. Ann Intern Med. 1997; 126:849-857. [PubMed: 9163285]

98. Cabrera J, Maynar M, Granados R, et al. Transjugular intrahepatic portosystemic shunt versus sclerotherapy in the elective treatment of variceal hemorrhage. Gastroenterology. 1996; 110:832839. [PubMed: 8608893]

99. Barton RE, Rosch J, Saxon RR, et al. TIPS: short- and long-term results: a survey of 1750 patients. Semin Interv Radiol. 1995; 12:364-367.

100. Boyer TD, Haskal ZJ. American Association for the Study of Liver Diseases. The Role of Transjugular Intrahepatic Portosystemic Shunt (TIPS) in the Management of Portal Hypertension: update 2009. Hepatology. 2010; 51(1):306. [PubMed: 19902484]

101. Moitinho E, Escorsell A, Bandi JC, et al. Prognostic value of early measurements of portal pressure in acute variceal bleeding. Gastroenterology. 1999; 117:626-31. [PubMed: 10464138]

102. Abraldes JG, Villanueva C, Banares R, et al. Hepatic venous pressure gradient and prognosis in patients with acute variceal bleeding treated with pharmacologic and endoscopic therapy. $\mathrm{J}$ Hepatol. 2008; 48:229-36. [PubMed: 18093686]

103. Monescillo A, Martinez-Lagares F, Ruiz-del-Arbol L, et al. Influence of portal hypertension and its early decompression by TIPS placement on the outcome of variceal bleeding. Hepatology. 2004; 40:793-801. [PubMed: 15382120]

104. Garcia-Pagan JC, Caca K, Bureau C, et al. Early use of TIPS in patients with cirrhosis and variceal bleeding. N Engl J Med. 2010; 362:2370-9. [PubMed: 20573925] 
105. Garcia-Pagán JC, Di Pascoli M, Caca K, et al. Use of early-TIPS for high-risk variceal bleeding: results of a post-RCT surveillance study. J Hepatol. 2013; 58(1):45-50. [PubMed: 22940408]

106. de Franchis R. Revising consensus in portal hypertension: report of the Baveno V consensus workshop on methodology of diagnosis and therapy in portal hypertension. J Hepatol. 2010; 53:762-8. [PubMed: 20638742]

107. Harman DJ, McCorry RB, Jacob RP, et al. Economic modelling of early transjugular intrahepatic portosystemic shunt insertion for acute variceal haemorrhage. Eur J Gastroenterol Hepatol. 2013; 25(2):201-7. [PubMed: 23089879]

108. Kanagawa H, Mima S, Kouyama H, et al. Treatment of gastric fundal varices by balloonoccluded retrograde transvenous obliteration. J Gastroenterol Hepatol. 1996; 11(1):51-58. [PubMed: 8672742]

109. Kiyosue H, Mori H, Matsumoto S, et al. Transcatheter obliteration of gastric varices. Part 1. Anatomic classification. Radiographics. 2003; 23(4):911-920. [PubMed: 12853665]

110. Kiyosue H, Mori H, Matsumoto S, et al. Transcatheter obliteration of gastric varices: Part 2. Strategy and techniques based on hemodynamic features. Radiographics. 2003 Jul-Aug;23(4): 921-37. discussion 937. [PubMed: 12853666]

111. Chikamori F, Kuniyoshi N, Shibuya S, Takase Y. Transjugular retrograde obliteration for chronic portosystemic encephalopathy. Abdom Imaging. 2000; 25:567-571. [PubMed: 11029085]

112. Hiraga N, Aikata $\mathrm{H}$, Takaki S, et al. The long-term outcome of patients with bleeding gastric varices after balloon-occluded retrograde transvenous obliteration. J Gastroenterol. 2007; 42(8): 663-672. [PubMed: 17701130]

113. Saad WEA, Darcy MD. Transjugular intrahepatic portosystemic shunt (TIPS) versus balloonoccluded retrograde transvenous obliteration (BRTO) for the management of gastric varices. Semin Intervent Radiol. 2011; 28:339-349. [PubMed: 22942552]

114. Saad WEA, Sabri SS. Balloon-occluded retrograde transvenous obliteration (BRTO): technical results and outcomes. Semin Intervent Radiol. 2011; 28:333-338. [PubMed: 22942551]

115. Saad WEA. The history and evolution of balloon-occluded retrograde transvenous obliteration (BRTO): from the United States to Japan and back. Semin Intervent Radiol. 2011; 28:283-287. [PubMed: 22942545]

116. Al-Osaimi AMS, Sabri SS, Caldwell SH. Balloon-occluded retrograde transvenous obliteration (BRTO): preprocedural evaluation and imaging. Semin Intervent Radiol. 2011; 28:288-295. [PubMed: 22942546]

117. García-Pagán JC, Caca K, Bureau C, et al. Early use of TIPS in patients with cirrhosis and variceal bleeding. N Engl J Med. 2010; 362:2370-2379. [PubMed: 20573925]

118. Garcia-Tsao G, Bosch J. Management of varices and variceal hemorrhage in cirrhosis. N Engl J Med. 2010; 362(9):823-832. [PubMed: 20200386]

119. Kitamoto M, Imamura M, Kamada K, et al. Balloon-occluded retrograde transvenous obliteration of gastric fundal varices with hemorrhage. AJR Am J Roentgenol. 2002; 178:1167-1174. [PubMed: 11959725]

120. Akahoshi T, Hashizume M, Tomikawa M, et al. Long-term results of balloon-occluded retrograde transvenous obliteration for gastric variceal bleeding and risky gastric varices: a 10-year experience. J Gastroenterol Hepatol. 2008; 23:1702-1709. [PubMed: 18713295]

121. Cho SK, Shin SW, Lee IH, et al. Balloon-occluded retrograde transvenous obliteration of gastric varices: outcomes and complications in 49 patients. AJR Am J Roentgenol. 2007; 189:W365-72. [PubMed: 18029851]

122. Belghiti J, Grenier P, Nouel O, et al. Long-term loss of Warren's shunt selectivity. Angiographic demonstration. Arch Surg. 1981; 116:1121-1124. [PubMed: 7283708]

123. D'Amico G, Pagliaro L, Bosch J, et al. The treatment of portal hypertension: a meta-analytic review. Hepatology. 1995; 22:332-354. [PubMed: 7601427]

124. Jalan R, John TG, Redhead DN, et al. A comparative study of emergency transjugular intrahepatic portosystemic stent-shunt and esophageal transection in the management of uncontrolled variceal hemorrhage. Am J Gastroenterol. 1995; 90:1932-1937. [PubMed: 7484994] 
125. Sarfeh IJ, Rypins EB. Partial versus total portocaval shunt in alcoholic cirrhosis. Results of a prospective, randomized clinical trial. Ann Surg. 1994; 219:353-361. [PubMed: 8161260] 


\section{KEY POINTS}

- Initial stabilization and resuscitation is imperative in the management of acute variceal bleeding along with attention at prevention of associated complications such as hepatic encephalopathy, acute renal injury, SBP and sepsis.

- Urgent attention at achieving hemostasis through endoscopic means remains the key and should be supported by pharmacotherapy aiming at reducing portal venous pressure.

- Patients failing initial treatment should be rescued with TIPS, BRTO, or rarely surgical shunts. 


\section{Role of TIPS in variceal bleeding}

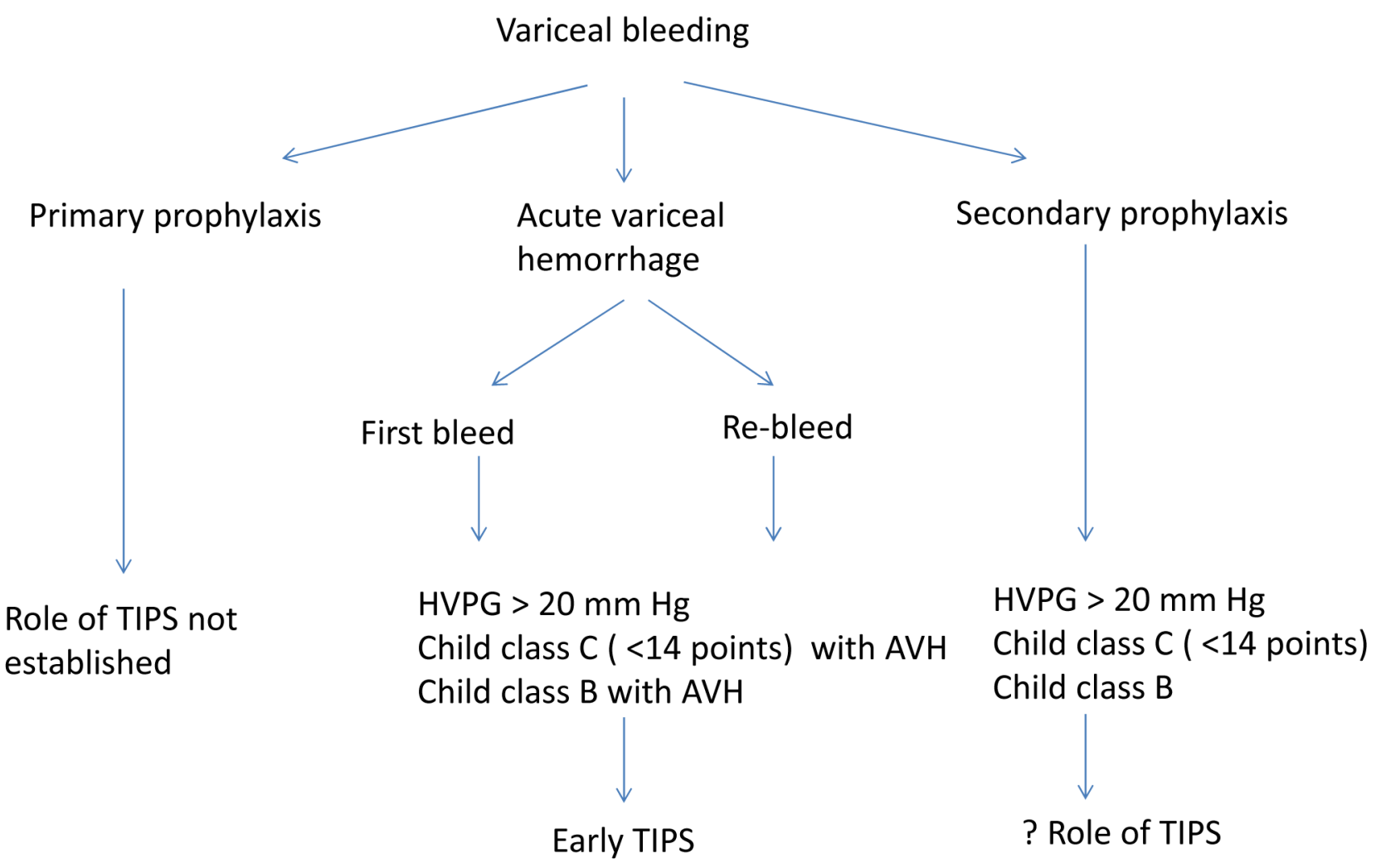

Figure 1. 